\title{
Bioactive and Antimicrobial Properties of Eggplant (Solanum melongena L.) under Microwave Cooking
}

\author{
Ahmad Mohammad Salamatullah *D, Mohammed Saeed Alkaltham, Khizar Hayat*, Mohammed Asif Ahmed (D), \\ Shaista Arzoo (D), Fohad Mabood Husain and Abdulhakeem Alzahrani

\begin{abstract}
Department of Food Science \& Nutrition, College of Food and Agricultural Sciences, King Saud University, Riyadh 11451, Saudi Arabia; malkaltham@ksu.edu.sa (M.S.A.); masifa@ksu.edu.sa (M.A.A.); sarzoo@ksu.edu.sa (S.A.); fhusain@ksu.edu.sa (F.M.H.); aabdulhakeem@ksu.edu.sa (A.A.)

* Correspondence: asalamh@ksu.edu.sa (A.M.S.); khayat@ksu.edu.sa (K.H.)
\end{abstract}

Citation: Salamatullah, A.M.; Alkaltham, M.S.; Hayat, K.; Ahmed, M.A.; Arzoo, S.; Husain, F.M.; Alzahrani, A. Bioactive and Antimicrobial Properties of Eggplant (Solanum melongena L.) under Microwave Cooking. Sustainability 2021, 13, 1519. https://doi.org/ $10.3390 /$ su13031519

Academic Editor: Giuseppe Marotta Received: 14 December 2020

Accepted: 27 January 2021

Published: 1 February 2021

Publisher's Note: MDPI stays neutral with regard to jurisdictional claims in published maps and institutional affiliations.

Copyright: (c) 2021 by the authors. Licensee MDPI, Basel, Switzerland. This article is an open access article distributed under the terms and conditions of the Creative Commons Attribution (CC BY) license (https:/ / creativecommons.org/licenses/by/ $4.0 /)$.
Abstract: Fruits and vegetables constitute a considerable amount of antioxidants and among them eggplant is a rich source of polyphenol compounds. This study investigated the bioactive and antimicrobial properties of eggplant under different degree of microwave cooking. The eggplant was cooked for $7 \mathrm{~min}$ (light cooked), $10 \mathrm{~min}$ (medium cooked), and $15 \mathrm{~min}$ (high cooked). The highest total polyphenol content was observed in the light cooked eggplant sample (27.35 mg gallic acid equivalent (GAE)/g dry weight (DW)) followed by high cooked sample $(26.10 \mathrm{mg}$ GAE/g DW), while the lowest total polyphenol content (2.79 mg GAE/g DW) was obtained for the uncooked (control) sample. The total polyphenol content of the samples ranged in the following order; light cooked $>$ high cooked $>$ medium cooked $>$ uncooked. The 2,2-diphenyl-1-picrylhydrazyl (DPPH) scavenging of eggplant ranged between $16.16 \%$ (control) and $47.88 \%$ (high cooked). The highest reducing power was exhibited by the light cooked (absorbance 1.708) eggplant sample followed by the high cooked (absorbance 1.597), while the lowest reducing power was shown by uncooked sample (absorbance 0.389). Moreover, antimicrobial studies showed that light cooked eggplant sample demonstrated broad-spectrum inhibition of growth in Gram-positive as well as Gram-negative bacteria and Candida albicans. Slightly lower antimicrobial potential was exhibited by medium cooked eggplant sample while no antibacterial or antifungal activity was recorded for the extract of high cooked eggplant sample. Microwave cooking might be a method to enhance the antioxidant and antimicrobial potential of eggplant.

Keywords: microwave cooking; eggplant; total flavonoid content; antioxidant activity; antimicrobial activity

\section{Introduction}

Fruits and vegetables constitute influential amount of antioxidants [1]. Eggplant (Solanum melongena L.) is a rich source of polyphenol compounds which lead it to be among the top ten vegetables having oxygen radical absorbance capacity [2,3]. Human body contains two defense systems, which include antioxidant enzymes like catalase, peroxidase, and superoxide dismutase and dietary antioxidants like ascorbic acid and tocopherol [4]. Polyphenol compounds are found in most parts of the eggplant, including calyx, leaf, peel, pulp, and stem [5]. Most common polyphenol in eggplant pulp is chlorogenic acid, which constitutes $70 \%$ to $90 \%$ of all the polyphenol contents [6-8].

Previous studies demonstrated that quality and quantity of polyphenols present in the eggplant were not sustainable and they were either noticeably decreased or increased by cooking, cultivar, and environment $[9,10]$. The upsurge in antioxidant activity of some vegetables after cooking might be due to the reasons such as the production of stronger radical-scavenging antioxidants, suppression of the oxidation capacity of antioxidants, or the thermal destruction of cell walls and sub cellular compartments which liberate more amounts of antioxidant components [11]. 
In general, boiling, steaming, and frying are three common cooking practices which have drastic effects on the sustainability of polyphenol contents [12]. In Middle East, deep frying is the most commonly used cooking method of eggplant. It is a dehydration process and the simultaneous heat and mass transfer between oil, food, and air, which leads to a series of physical and chemical changes in the foodstuff [13]. Deep frying also increases the calorie contents of meal and sometime reduces the total polyphenol contents related to the thermos-stability of the phenolic fraction [14,15]. Furthermore, eggplant capable of absorbing large amounts of frying oils, can lead to their oxidation [16]. Lipid oxidation is a series of reactions producing a number of harmful breakdown products [17]. Sustainability of phenolic contents during cooking depends on various factors such as cooking time, ratio between water and vegetable, and surface size [18]. A cooking method could be preferred for each vegetable to preserve the polyphenol contents [14].

Over a period of numerous decades, the microwave heating has gained the popularity in the area of food processing due to its capability to achieve high heating rates, safe handling, substantial reduction in cooking time, and easiness in operation, and a little maintenance [19]. In a study on cv. Agria potatoes, the researchers investigated the change in the phenolic constituents during microwave baking at different microwave level. They reported that the phenolic compounds were retained at a decent level when samples were cooked at $500 \mathrm{~W}$ [20]. Another study assessed the effects of different cooking methods such as boiling, steaming, and microwaving on the nutritional and physical properties of carrots, cauliflowers, and sweet potatoes. The authors had reported that as compared to boiling and steaming the losses in ascorbic acid concentrations were least in microwaving and it also preserved carotenoids and increased the total phenolics [21]. It has also been found to increase the total phenolic content of carrots [22,23].

In addition to the antioxidant properties, Solanum melongena has also been reported for its antimicrobial action against various pathogenic bacteria and fungi [24]. Presence of compounds such as caffeic acid, chlorogenic acid, and flavonoids, such as nasunin, are responsible for a sustainable antimicrobial potential of the eggplant.

Previous studies demonstrated that the heat treatment either increased or decreased the antioxidant capacity and total phenolic content in eggplant $[25,26]$. However, very little information is available in the literature regarding the total polyphenol contents, antioxidant activity, and antimicrobial potential of microwave cooked eggplant. Vegetables comprise several hydrophilic and lipophilic antioxidant compounds and it is important to evaluate their antioxidant activity. Therefore, the present study was undertaken to investigate the effects of different degrees of microwave cooking of eggplant on its total polyphenol content, total flavonoid content, antimicrobial activity, and the antioxidant activity in terms of DPPH (2,2-dipheny-l-picrylhydrazyl), and reducing power.

\section{Materials and Methods}

\subsection{Microwave Cooking and Sample Preparation}

The black long-shaped eggplants with intermediate size were purchased from a local market in Riyadh, Saudi Arabia. The whole eggplant was pierced and placed in a household microwave oven. The heating of the eggplant was performed at $900 \mathrm{~W}$ for three different times as, $7 \mathrm{~min}$ ( $5 \mathrm{~min}$ heating and then the sample was turned and heated for another $2 \mathrm{~min}$ ), $10 \mathrm{~min}$ (7 $\mathrm{min}$ heating, then after turning the sample, it was heated for another $3 \mathrm{~min}$ ), and $15 \mathrm{~min}$ (10 $\mathrm{min}$ heating and then $5 \mathrm{~min}$ heating after turning the sample). These samples were termed as light cooked, medium cooked, and high cooked, respectively. All these samples were prepared in triplicates. The unheated eggplant was used as a control. After cooking, the samples were cooled to room temperature $\left(23^{\circ} \mathrm{C}\right)$ and then they were peeled off with knife and cut into uniform pieces of $1 \mathrm{~cm}$ thickness. The samples were then freeze-dried (Alpha 1-4 LDPlus, Christ; Osterode, Germany) for $72 \mathrm{~h}$ at $-50{ }^{\circ} \mathrm{C}$ and 0.05 mbar pressure. The dried samples (moisture content $7 \%$ on dry basis) were ground into powder and the material which passed through 60 mesh sieve was stored in air-tight plastic bags at room temperature for further use. 


\subsection{Extraction}

The eggplant sample $(2 \mathrm{~g})$ was extracted with $20 \mathrm{~mL}$ of $80 \%$ ethanol employing ultrasound extraction for $45 \mathrm{~min}$ at $23^{\circ} \mathrm{C}$. The mixture was then centrifuged at $3000 \times g$ for $10 \mathrm{~min}$ at room temperature. The supernatant was then filtered using a Whatman filter paper number 2 . The extract was stored at $4{ }^{\circ} \mathrm{C}$ for further use.

\subsection{Total Polyphenol Content}

Total polyphenol content (TPC) was estimated using Folin-Ciocalteu method according to the procedure suggested by Hayat [27]. Briefly, $0.025 \mathrm{~mL}$ of eggplant extract was added to $0.125 \mathrm{~mL}$ of undiluted Folin-Ciocalteu reagent and then $1.5 \mathrm{~mL}$ distilled water was added to the mixture. The mixture was shaken at room temperature for $1 \mathrm{~min}$ and then $0.375 \mathrm{~mL}$ of $20 \%$ sodium carbonate was added. The final volume of the mixture was prepared to $2.5 \mathrm{~mL}$ by adding $0.475 \mathrm{~mL}$ water. The prepared mixture was incubated for $30 \mathrm{~min}$ at room temperature and then detection of the phenols was achieved spectroscopically at $760 \mathrm{~nm}$. The TPC was expressed as milligram gallic acid equivalent per gram dry weight of the sample (mg GAE/g DW).

\subsection{Total Flavonoid Content}

Total flavonoid content (TFC) was estimated according to the method suggested by Hayat [27]. Briefly, $0.25 \mathrm{~mL}$ of eggplant extract was mixed with $1 \mathrm{~mL}$ of water and then $0.075 \mathrm{~mL}$ of each $5 \%(w / v)$ sodium nitrite and $10 \%(w / v)$ aluminum chloride were added. Mixture was incubated for $5 \mathrm{~min}$ at room temperature and then $0.5 \mathrm{~mL}$ of $1 \mathrm{M}$ sodium hydroxide and $0.6 \mathrm{~mL}$ of water was added. Finally, the mixture was than vortexed and absorbance was measured spectroscopically at $510 \mathrm{~nm}$. Blank was prepared without extract. TFC was expressed as milligram catechin equivalent per gram dry weight of the sample (mg CE/g DW).

\subsection{DPPH Scavenging}

The free radical scavenging capacity of the extract was determined using DPPH according to the method suggested by Noreen et al., [28] with some modifications. An aliquot of extract $(0.13 \mathrm{~mL}$ ) and $0.1 \mathrm{mM}$ DPPH solution (prepared in methanol) was mixed and allowed to rest in the dark for $30 \mathrm{~min}$ and the control was also prepared in the same manner but ethanol was used instead of extract. Ethanol was used as a blank. The absorbance was measured spectroscopically at $510 \mathrm{~nm}$. The scavenging percentage was calculated as

$$
\mathrm{DPPH} \text { scavenging } \%=\text { Acontrol }- \text { Asample } / \text { Acontrol } \times 100
$$

\subsection{Reducing Power}

The ferric reducing power of the sample was determined according to the method of Hayat et al., [29]. The eggplant extract $(0.5 \mathrm{~mL})$ was mixed with $1.25 \mathrm{~mL}$ of phosphate buffer $(0.2 \mathrm{M}, \mathrm{pH} 6.6)$ and $1.25 \mathrm{~mL}$ of potassium ferricyanide and then incubated at $50{ }^{\circ} \mathrm{C}$ for $20 \mathrm{~min}$. Trichloroacetic acid $(1.25 \mathrm{~mL})$ was added after incubating the sample, and then the mixture was centrifuged at room temperature for $10 \mathrm{~min}$ at $3000 \times \mathrm{g}$. Finally, $1.25 \mathrm{~mL}$ of aliquot was taken from the supernatant, to which $1.25 \mathrm{~mL}$ water and $0.25 \mathrm{~mL}$ of ferric chloride was added, respectively. Blank was prepared without extract. The absorbance was recorded at $700 \mathrm{~nm}$.

\subsection{Antimicrobial Activity}

Agar well diffusion assay was performed with test pathogens (Staphylococcus aureus, Listeria monocytogenes, Pseudomonas aeruginosa, Escherichia coli, and Candida albicans) to determine the growth inhibition at the tested concentrations of extracts [30]. Briefly, Mueller Hinton agar (MHA) plates were spread with $0.1 \mathrm{~mL}$ of appropriately diluted $\left(2.5 \times 10^{-6} \mathrm{CFU} / \mathrm{mL}\right)$ freshly grown cultures. Agar wells were loaded with $1000 \mu \mathrm{g} / \mathrm{mL}$ 
concentration of the extracts. Solvent (5\% DMSO) and Mueller Hinton broth (MHB) were used as control. Plates were incubated for $18-24 \mathrm{~h}$ at $37^{\circ} \mathrm{C}$ to check the inhibition of growth around the wells. All the samples were analyzed in triplicates.

\subsection{Sugar Analysis}

Sugars were extracted according to the method of Lo Scalzo et al. [14] with slight modifications. Eggplant powder $150 \mathrm{mg}$ in $15 \mathrm{~mL}$ of $80 \%$ methanol $(v / v)$ was sonicated for $15 \mathrm{~min}$ then centrifuged at 12,000 rpm. The supernatant was collected then another $15 \mathrm{~mL}$ of $80 \%$ methanol were added, and then the sonication and centrifugation process was repeated as earlier. The supernatant was collected, combined, and the volume was made up to the mark with $80 \%$ methanol in a $50 \mathrm{~mL}$ volumetric flask. The sample was filtered through a $0.45 \mu \mathrm{m}$ syringe filters before injection to an HPLC. Sugars were analyzed using Shimadzu prominence LC-10AB pump (Kyoto, Japan), using a mobile phase of $80 \%$ aqueous acetonitrile at an isocratic flow rate of $1 \mathrm{~mL} / \mathrm{min}$. Sugars were separated with a Shimadzu LC-NH2 column $(15 \times 4.6 \mathrm{~mm})$, and identified with RID-10A Shimadzu detector. Sugars in eggplant samples were identified by comparing their peak retention time with those of standards and quantified using Shimadzu LabSolutions, Lcsolution workstation V 1.22. All the samples were analyzed in duplicates.

\subsection{HPLC Analysis of Phenolic Compounds}

The quantification of phenolic compounds (tannic acid, resorcinol, 1,2-dihydroxybenzene, chlorogenic acid, caffeic acid, vanillin, acetyl salicylic acid, 3,5-dinitrosalicylic acid, salicylic acid, and quercetin) in eggplant samples were determined using HPLC with the method described previously with slight modifications [31]. The HPLC system Shimadzu, prominence (Kyoto, Japan) equipped with LC-20AB binary pump and a variable Shimadzu SPD-10A UV detector was used for the analysis. The column employed was Zorbax SB-C 18 $(250 \times 4.6 \mathrm{~mm}, 5 \mu \mathrm{m})($ Agilent, Santa Clara, CA, USA) and the mobile phase Milli Q water $(1.0 \%$ Acetic acid, A) and $\mathrm{MeOH}(\mathrm{B})$ was used at a flow rate of $1.0 \mathrm{~mL} / \mathrm{min}$. The binary gradient program used was 0-10 $\min 15-30 \% \mathrm{~B} ; 10-20 \mathrm{~min} 30-40 \% \mathrm{~B} ; 20-30 \mathrm{~min} 40-50 \% \mathrm{~B}$; $30-41 \min 50-60 \% \mathrm{~B} ; 41-45 \min 15 \%$ B. The injection volume was $10 \mu \mathrm{L}$, and the detector was set at $280 \mathrm{~nm}$. Compounds in eggplant samples were identified by comparing their peak retention time with those of standards. All the samples were analyzed in duplicates.

\subsection{Statistical Analysis}

All the experiments (TPC, TFC and antioxidant activities) were performed in triplicate and the results were expressed as means \pm SD (standard deviation). One-way analysis of variance (ANOVA) at a significance level of $p \leq 0.05$ was used to analyze the differences among the treatment groups and if significant differences were found then a post-hoc analysis using Duncan's multiple range tests was performed by SAS (Version 9.2, 20002008; SAS Institute Inc., Cary, NC, USA). For antimicrobial studies Student's $t$-test was performed to determine the significance between control and test sample groups.

\section{Results and Discussion}

\subsection{Effect of Microwave Cooking on Total Polyphenol Content of Eggplant}

As shown in Figure 1, the microwave cooking significantly $(p<0.05)$ changed the total polyphenol content (TPC) of eggplant. The highest TPC was observed in the light cooked eggplant (27.35 mg GAE/g DW) followed by the high cooked sample (26.10 mg GAE/g DW). However, statistically there was no significant difference in the TPC of these samples. Medium cooked sample exhibited significantly lower TPC than light- and high cooked samples but the lowest total polyphenol content (2.79 mg GAE/g DW) was obtained for the uncooked (control) sample. In a study, the TPC of the raw eggplant (Solanum melongena L.) was found to be $298.5 \mathrm{mg} \mathrm{GAE} / 100 \mathrm{~g} \mathrm{DW}$ which is almost in accordance with the values obtained in our study [32]. Kaur et al., [33] determined the TPC of different varieties of eggplant which ranged from 244.28 to $2990.64 \mathrm{mg}$ GAE/100 g DW. 
The results of our study showed that the microwave cooking significantly increased the TPC of eggplant. Many studies described that microwave heating can increase the TPC of the plant samples and this was attributed to the release of phenolic compounds from plant matrix on microwave $[29,34,35])$. In contrary, a $27 \%$ loss in total polyphenol content was recorded for an optimized microwave cooking process of courgette but it was still lower than that by conventional cooking (40\%) [36]. The TPC of eggplant was decreased by grilling at a temperature below $65^{\circ} \mathrm{C}$ [37].

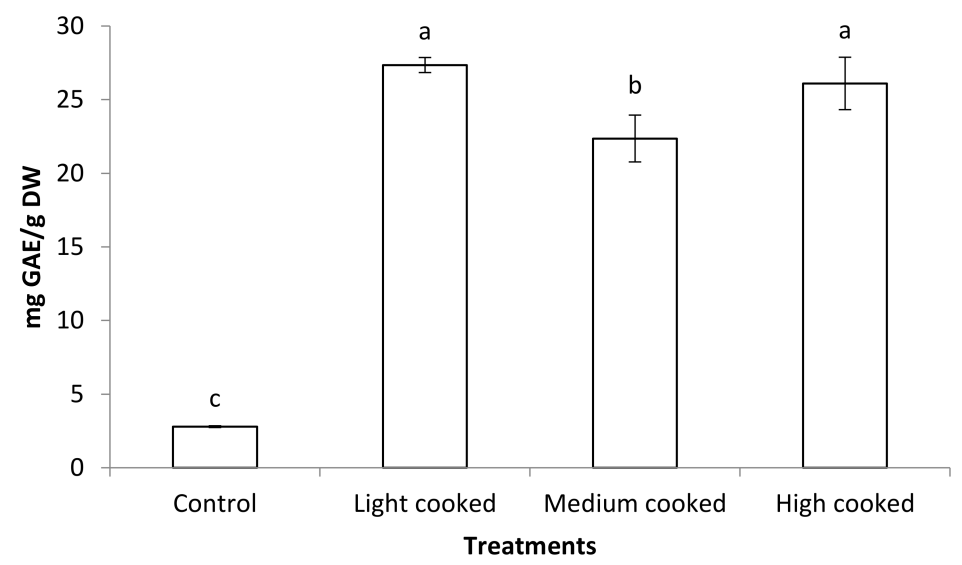

Figure 1. Effect of microwave cooking on total polyphenol content of eggplant. Different letters on each data are for statistically significant difference, $(p<0.05)$.

\subsection{Effect of Microwave Cooking on Total Flavonoid Content of Eggplant}

The effect of microwave cooking on total flavonoid content (TFC) of eggplant is shown in Figure 2. In a similar way like TPC, the TFC of eggplant was significantly increased in microwave cooked eggplant samples. The TFC of the microwave cooked samples ranged in the following order light cooked $>$ high cooked $>$ medium cooked. There was no significant difference between the TFC of light cooked (19.27 mg CE/g DW) and high cooked samples (19.12 mg CE/g DW) while the uncooked sample exhibited significantly lowest TFC $(p<0.05)$ among all the samples. The flavonol contents were increased in eggplants after frying, grilling, and baking process [25]. Microwave cooking alone or in combination with steaming improved the total flavonoid content of sweet potatoes [38].

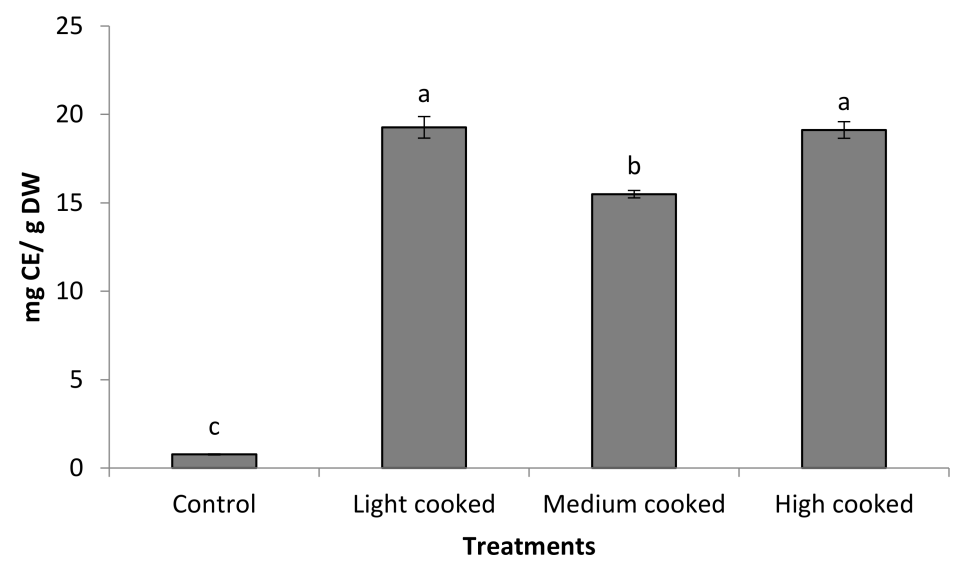

Figure 2. Effect of microwave cooking on total flavonoid content of eggplant. Different letters on each data are for statistically significant difference, $(p<0.05)$.

\subsection{Effect of Microwave Cooking on DPPH Scavenging of Eggplant}

The DPPH scavenging of the eggplant as affected by microwave cooking is shown in Figure 3. At a concentration of $5 \mathrm{mg} / \mathrm{mL}$ the DPPH scavenging of eggplant ranged between $16.16 \%$ (control) and $47.88 \%$ (high cooked). No significant difference was noted 
for the DPPH scavenging capacity of high cooked and light cooked (46.24\%) eggplant while medium cooked eggplant sample exhibited a significantly different $(p<0.05)$ DPPH scavenging potential $(34.70 \%)$. Such outcomes could be due to the complexity of the chemical reactions during microwave cooking process. Some of the phenolic compounds like chlorogenic acids go under degradation, autoxidation, and polymerization during roasting process which in turn could decrease the total polyphenol content and the antioxidant activity of the plant samples [39,40]. On the other hand, such degradation may also involve the release of some other bioactive compounds like hydroxycinnamates and quinic acid [41]. Furthermore, due to high temperature during prolonged cooking, the Maillard reaction takes place, producing a number of compounds which can contribute to the antioxidant activity of the product [42]. Consequently, all of the compounds that appear during roasting process could either compensate for the loss of some substances or even contribute towards the increase in antioxidant activity [43] The grilled eggplant presented a higher antioxidant activity than that of the raw fruits [44]. In another study, the antioxidant activity of purple eggplant was decreased while the white eggplant was increased upon microwave cooking as compared to the raw fruits [45]. The DPPH scavenging was increased with the increase of temperature when the eggplants were grilled at a temperature between $65^{\circ} \mathrm{C}$ and $95^{\circ} \mathrm{C}$ and this increase was ascribed to the collapsed cells, inter-tissue cracks, and thin intracellular bonds around the middle area of the eggplant fruits [37]. Microwave processing usually better retains the constituents of fruits and vegetables and increases their antioxidant activity [46].

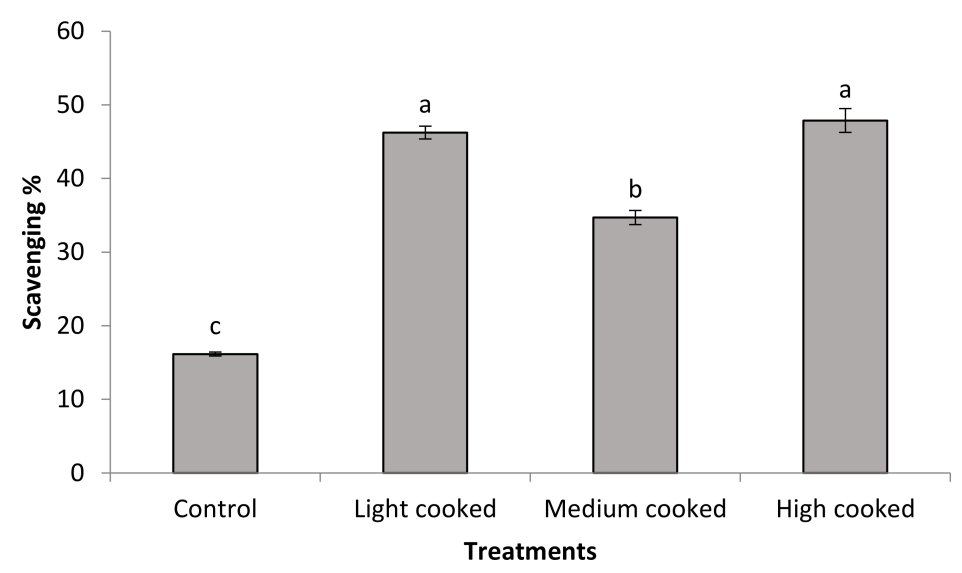

Figure 3. Effect of microwave cooking on DPPH scavenging eggplant. Different letters on each data are for statistically significant difference, $(p<0.05)$.

\subsection{Effect of Microwave Cooking on Reducing Power of Eggplant}

The ferric ion reducing power of raw and microwave cooked eggplant is shown in Figure 4. The reducing power of eggplant samples showed a similar trend as that of the DPPH scavenging. All the samples were tested at a concentration of $1 \mathrm{mg} / \mathrm{mL}$ and the microwave cooked samples showed a significantly higher reducing power than the uncooked sample. The highest reducing power was exhibited by the light cooked (absorbance $(\mathrm{Abs})=1.708)$ eggplant sample followed by high cooked $(\mathrm{Abs}=1.597)$ one, while the lowest reducing power was shown by the uncooked sample (0.389). The results of reducing power and DPPH scavenging echoed the trend of TPC and TFC of the eggplant samples which showed that the antioxidant capacity of the samples was in a part due to their phenolic contents. The antioxidant activity and the chlorogenic acid content were increased in the grilled eggplants as compared to the raw sample [14]. Total phenolic content and antioxidant activity was increased in heat treated eggplants as compared to the raw samples $[47,48]$. The reducing power of the fried, grilled and baked eggplants was improved as compared to the raw eggplant sample [25]. 


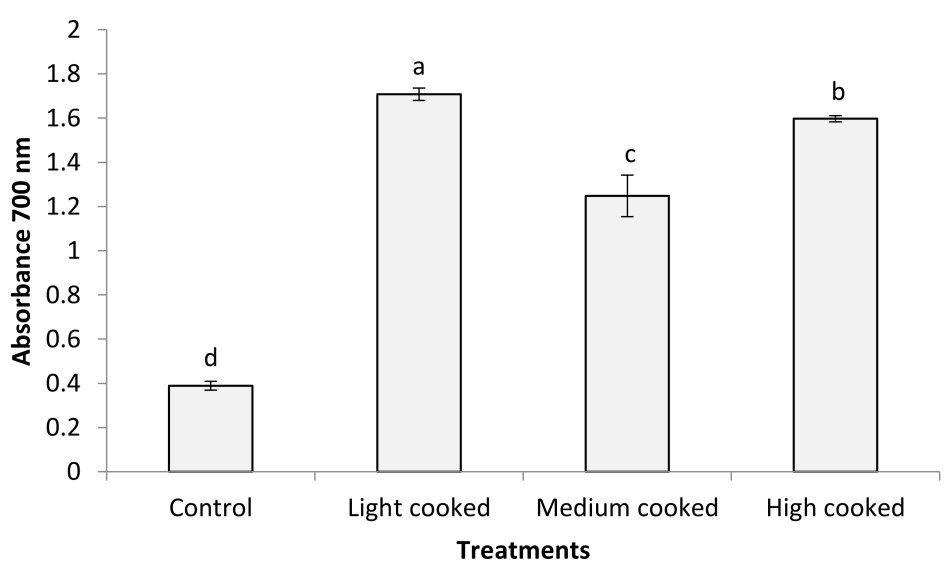

Figure 4. Effect of microwave cooking on reducing power of eggplant. Different letters on each data are for statistically significant difference, $(p<0.05)$.

\subsection{Antimicrobial Activity}

Extracts of uncooked and microwave cooked eggplants were assessed for their antimicrobial activity against bacterial and fungal pathogens (Table 1 ). At $1 \mathrm{mg} / \mathrm{mL}$ concentration of the extracts, the highest antimicrobial activity was demonstrated by the light cooked sample. The extract of light cooked sample showed the inhibition zones of 16, 19, 15, 18, and $20 \mathrm{~mm}$ against S. aureus, L. monocytogenes, P. aeruginosa, E. coli, and C. albicans, respectively. Slightly lower zones of bacterial growth inhibition were observed with the extract of medium cooked sample while no antimicrobial activity was recorded for the extract of the high cooked sample. Uncooked sample extract demonstrated both antibacterial and anticandidal activity but it was less than the light and medium cooked sample. Antibiotics (Imipenem and ceftazidime) and antifungal (Nystatin) agents were used as positive control for assessing the antibacterial activity. Our results clearly showed that the antimicrobial potential was enhanced at low and medium microwave cooking as compared to the uncooked eggplant sample. This is a significant finding indicating that microwave cooking can increase the antimicrobial potential of the eggplant.

Table 1. Antimicrobial activity of the extracts of microwave cooked and uncooked eggplant samples on dry weight basis. Data is presented as mean \pm standard deviation. ${ }^{*}$ denotes significance at $p \leq 0.05$. ND $=$ Not detected.

\begin{tabular}{|c|c|c|c|c|c|c|}
\hline \multirow[t]{2}{*}{ S. No } & \multirow[t]{2}{*}{ Sample } & \multicolumn{5}{|c|}{ Zone of Inhibition (mm) } \\
\hline & & S. aureus & L. monocytogenes & E. coli & P. aeruginosa & C. albicans \\
\hline 1. & Control & $11 \pm 1.3$ & $14 \pm 1.7$ & $13 \pm 0.9$ & $11 \pm 0.5$ & $13 \pm 1.7$ \\
\hline 2. & low & $16 \pm 1.0 *$ & $19 \pm 0.5 *$ & $15 \pm 2.1$ & $18 \pm 1.0 *$ & $20 \pm 0.7$ * \\
\hline 3. & medium & $14 \pm 0.6$ & $13 \pm 0.8$ & $14 \pm 1.3$ & $15 \pm 1.4^{*}$ & $16 \pm 0.9$ * \\
\hline 4. & high & ND & ND & ND & ND & ND \\
\hline 5. & Imipenem & $20 \pm 2.0 *$ & $22 \pm 1.5^{*}$ & - & - & - \\
\hline 6. & Ceftazidime & - & - & $19 \pm 0.6^{*}$ & $20 \pm 1.5^{*}$ & - \\
\hline 7. & Nystatin & - & - & - & - & $22 \pm 1.8^{*}$ \\
\hline
\end{tabular}

\subsection{Sugar Analysis}

The concentration of fructose, glucose and sucrose in eggplant were analyzed and reported in Table 2. Glucose and fructose are predominant reducing sugars in eggplant samples, and their concentrations were higher than that of sucrose. In accordance with a previous study reported by Lo Scalzo et al., [14], the simple sugar content generally was quite stable after microwave cooking. Sugar content found are in the range of 1-18\% in control, where as in the range of $2.3-17 \%, 2-18 \%$ and $2.6-18 \%$ in light, medium, and high cooked eggplant samples, respectively. Hansan et al. [49] reported sugar content in eggplant in the range of $20-30 \%$. 
Table 2. Sugar analysis (dry weight basis).

\begin{tabular}{cccc}
\hline Samples/Sugars & Fructose $(\mathbf{g} / \mathbf{1 0 0} \mathbf{g})$ & Glucose $(\mathbf{g} / \mathbf{1 0 0} \mathbf{g})$ & Sucrose $(\mathbf{g} / \mathbf{1 0 0} \mathbf{g})$ \\
\hline Control & $18.17 \pm 0.23$ & $17.27 \pm 0.19$ & $0.933 \pm 0.09$ \\
Light cooked & $17.27 \pm 0.11$ & $15.9 \pm 0.17$ & $2.3 \pm 0.16$ \\
Medium cooked & $18.13 \pm 0.21$ & $17.3 \pm 0.13$ & $2.0 \pm 0.13$ \\
High cooked & $18.17 \pm 0.19$ & $17.17 \pm 0.21$ & $2.6 \pm 0.17$ \\
\hline
\end{tabular}

\subsection{HPLC Analysis of Phenolic Compounds}

The average quantities of phenolic compounds detected in eggplant samples are reported in Table 3, and the phenolic compounds Figure 5 which were not detected had not been listed in Table 3. The HPLC results showed the lowest concentration of the phenolic compounds in uncooked (raw) eggplant (Figure 6) as compared to those of the cooked eggplant samples (Figure 7) and these results are similar to the aforementioned antioxidant activity results of the eggplant samples. Light cooked sample had the highest phenolic compounds $(2.8 \mathrm{~g} / 100 \mathrm{~g})$ compared to the medium cooked $(2.3 \mathrm{~g} / 100 \mathrm{~g})$ and high cooked (1.6 g/100 g) samples.

Table 3. HPLC results (mg/100 $\mathrm{g}$ dry weight) of the phenolic compounds in eggplant.

\begin{tabular}{ccccc}
\hline Phenolic Compound & Uncooked & Light Cooked & Medium Cooked & High Cooked \\
\hline Tannic Acid & $53.5 \pm 0.13$ & - & - & - \\
Resorcinol & $8.7 \pm 0.09$ & $210.5 \pm 0.23$ & $206.5 \pm 0.31$ & $124 \pm 0.51$ \\
1,2-Dihydroxy Benzene & $5.7 \pm 0.15$ & - & - & - \\
Chlorogenic Acid & $17 \pm 0.11$ & $2543 \pm 1.07$ & $2119.5 \pm 1.03$ & $1490.5 \pm 1.13$ \\
Caffeic Acid & $1.5 \pm 0.21$ & $9.1 \pm 0.11$ & - & - \\
Vanillin & $0.45 \pm 0.07$ & $44.2 \pm 0.13$ & $34 \pm 0.09$ & $23 \pm 0.11$ \\
Total & $86.85 \pm 0.76$ & $2806.8 \pm 1.54$ & $2360 \pm 1.43$ & $1637.5 \pm 1.64$ \\
\hline
\end{tabular}

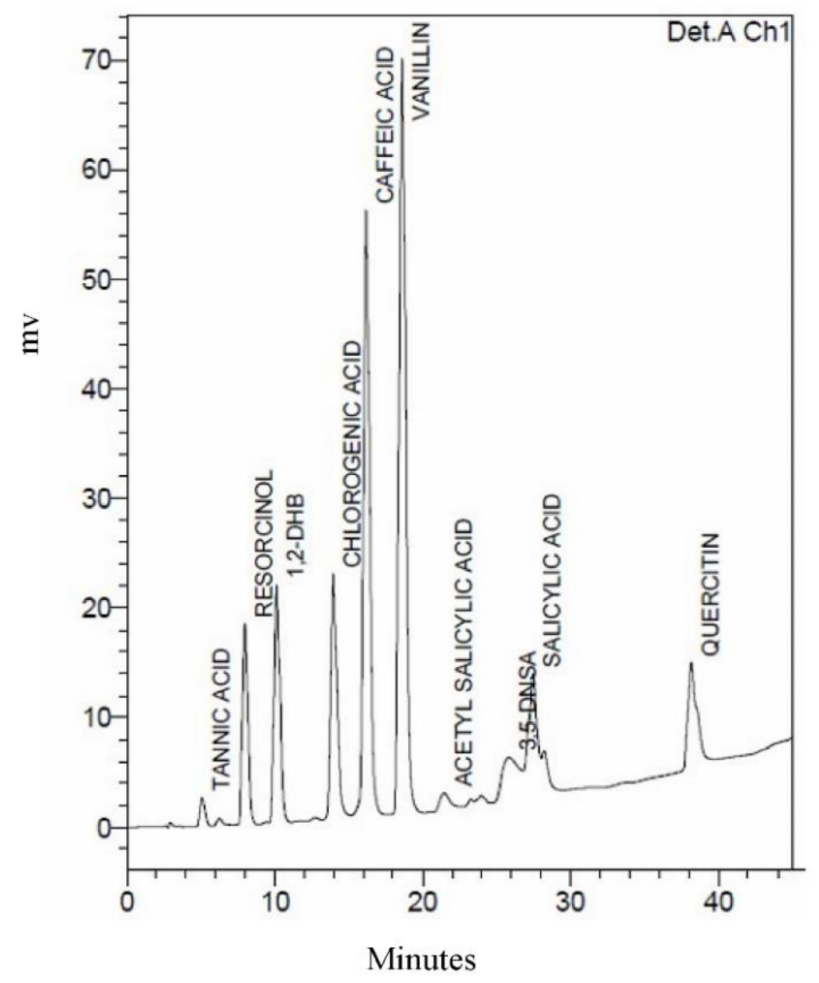

Figure 5. HPLC chromatogram of standard compounds. 


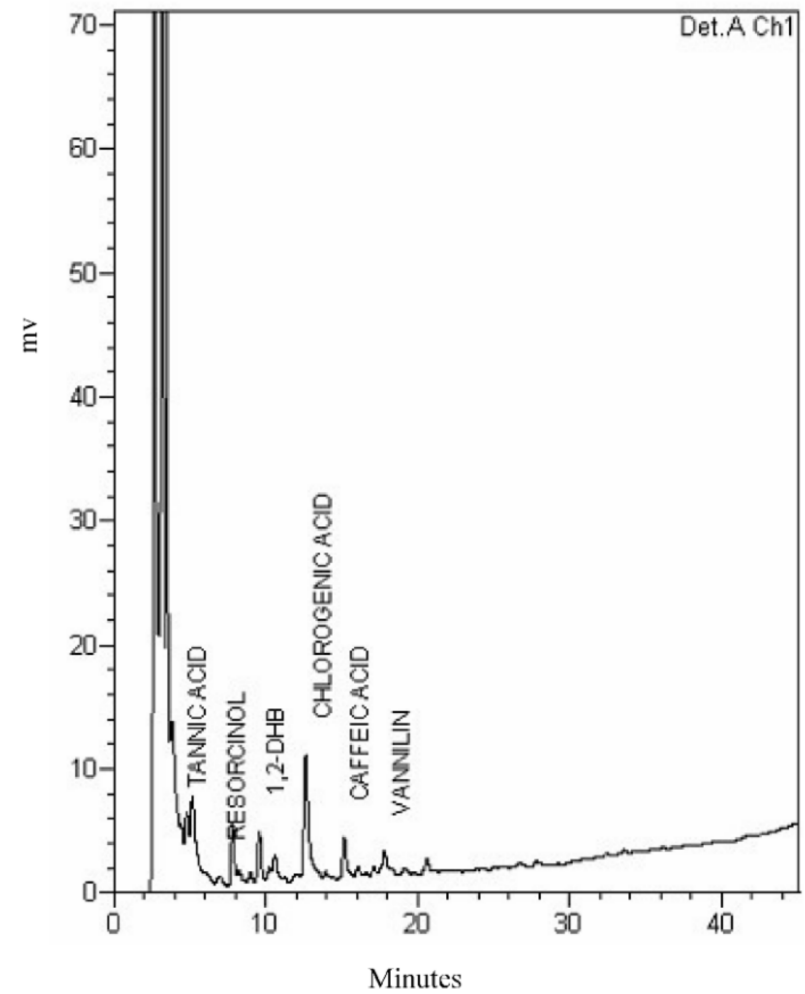

Figure 6. HPLC chromatogram of uncooked eggplant.

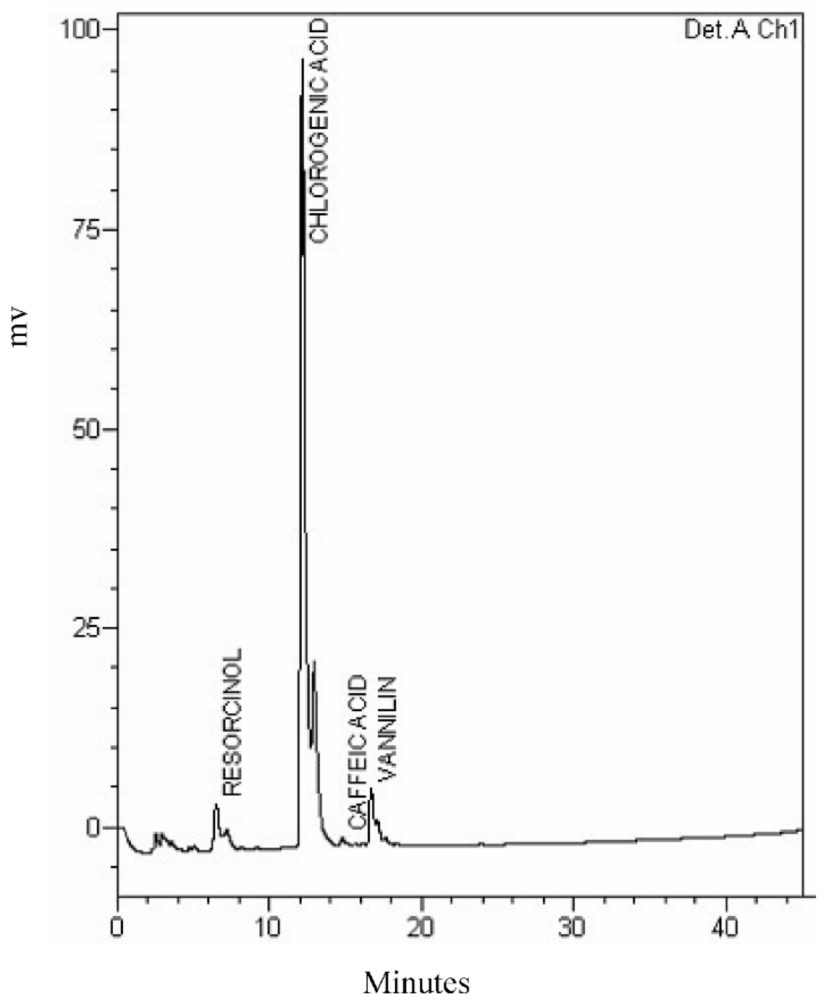

Figure 7. HPLC chromatogram of light cooked eggplant.

Chlorogenic acid was the predominant phenolic compound in cooked eggplant samples; similar results are reported by [50-52]. Chlorogenic acid peak area average in the HPLC chromatogram were of $41.3 \%$ for light cooked, $34.4 \%$ for medium cooked, and $24.2 \%$ for high cooked eggplant samples. For all samples the Chlorogenic acid peak area in the 
chromatogram account for about $90 \%$ of the total peak area. These results are in agreement with the findings of Plazas et al., [53].

\section{Conclusions}

The effect of microwave cooking was investigated on the phenolic content, and antioxidant and antimicrobial potential of eggplant. Microwave cooking showed a profound effect on the eggplant and its TPC, TFC and antioxidant activity were increased significantly. The highest TPC, TFC, DPPH, and reducing power were exhibited by the light cooked sample while the lowest values were observed for the uncooked eggplant sample. Further, we observed that the antimicrobial potential was enhanced at low and medium cooking. Thus, it is envisaged that microwave cooking can be method to reap the maximum health benefits of eggplant. Exploring the exact mechanism for the increase of total phenols and antioxidant activity of eggplant by microwave cooking can be the spice for next study.

Author Contributions: Conceptualization, A.M.S., K.H., and M.S.A.; methodology, A.M.S., M.A.A., and K.H.; software, K.H. and F.M.H.; validation, A.M.S., M.S.A., and S.A.; formal analysis, K.H., F.M.H., M.A.A., and S.A; investigation, A.M.S. and A.A.; resources, A.M.S.; data curation, K.H. and A.A.; writing - original draft preparation, A.M.S., K.H., and M.S.A.; writing-review and editing, F.M.H., S.A., M.A.A., and A.A.; visualization, S.A. and K.H.; supervision, A.M.S. and K.H.; project administration, A.M.S. and M.S.A. All authors have read and agreed to the published version of the manuscript.

Funding: This research received no external funding.

Acknowledgments: The authors extend their appreciation to the Deanship of Scientific Research at King Saud University for funding this work through research group no (RG-1441-360).

Conflicts of Interest: The authors declare no conflict of interest.

\section{References}

1. Cömert, E.D.; Mogol, B.A.; Gökmen, V. Relationship between color and antioxidant capacity of fruits and vegetables. Curr. Res. Food Sci. 2020, 2, 1-10. [CrossRef] [PubMed]

2. Gürbüz, N.; Uluişik, S.; Frary, A.; Frary, A.; Doğanlar, S. Health benefits and bioactive compounds of eggplant. Food Chem. 2018, 268, 602-610. [CrossRef] [PubMed]

3. Niño-Medina, G.; Urías-Orona, V.; Muy-Rangel, M.D.; Heredia, J.B. Structure and content of phenolics in eggplant (Solanum melongena)—A review. South African J. Bot. 2017, 111, 161-169. [CrossRef]

4. Kalpna, R.; Mital, K.; Sumitra, C. Vegetable and fruit peels as a novel source of antioxidants. J. Med. Plants Res. $2011,5,63-71$.

5. Jung, E.J.; Bae, M.S.; Jo, E.K.; Jo, Y.H.; Lee, S.C. Antioxidant activity of different parts of eggplant. J. Med. Plant Res. 2011, 5, 4610-4615.

6. Gramazio, P.; Prohens, J.; Plazas, M.; Andújar, I.; Herraiz, F.J.; Castillo, E.; Knapp, S.; Meyer, R.S.; Vilanova, S. Location of chlorogenic acid biosynthesis pathway and polyphenol oxidase genes in a new interspecific anchored linkage map of eggplant. BMC Plant Biol. 2014, 14, 350. [CrossRef] [PubMed]

7. Plazas, M.; López-Gresa, M.P.; Vilanova, S.; Torres, C.; Hurtado, M.; Gramazio, P.; Andújar, I.; Herráiz, F.J.; Bellés, J.M.; Prohens, J. Diversity and relationships in key traits for functional and apparent quality in a collection of eggplant: Fruit phenolics content, antioxidant activity, polyphenol oxidase activity, and browning. J. Agric. Food Chem. 2013, 61, 8871-8879. [CrossRef]

8. Kalogeropoulos, N.; Chiou, A.; Mylona, A.; Ioannou, M.S.; Andrikopoulos, N.K. Recovery and distribution of natural antioxidants ( $\alpha$-tocopherol, polyphenols and terpenic acids) after pan-frying of Mediterranean finfish in virgin olive oil. Food Chem. 2007, 100, 509-517. [CrossRef]

9. Achouri, A.; Boye, J.I.; Belanger, D. Soybean isoflavones: Efficacy of extraction conditions and effect of food type on extractability. Food Res. Int. 2005, 38, 1199-1204. [CrossRef]

10. Naczk, M.; Shahidi, F. Extraction and analysis of phenolics in food. J. Chromatogr. A 2004, 1054, 95-111. [CrossRef]

11. Morales, F.J.; Babbel, M.-B. Antiradical efficiency of Maillard reaction mixtures in a hydrophilic media. J. Agric. Food Chem. 2002, 50, 2788-2792. [CrossRef] [PubMed]

12. Gunathilake, K.; Ranaweera, K.; Rupasinghe, H. Effect of different cooking methods on polyphenols, carotenoids and antioxidant activities of selected edible leaves. Antioxidants 2018, 7, 117. [CrossRef] [PubMed]

13. Teruel, M.d.R.; Gordon, M.; Linares, M.B.; Garrido, M.D.; Ahromrit, A.; Niranjan, K. A comparative study of the characteristics of French fries produced by deep fat frying and air frying. J. Food Sci. 2015, 80, E349-E358. [CrossRef] [PubMed]

14. Lo Scalzo, R.; Fibiani, M.; Francese, G.; D’Alessandro, A.; Rotino, G.L.; Conte, P.; Mennella, G. Cooking influence on physicochemical fruit characteristics of eggplant (Solanum melongena L.). Food Chem. 2016, 194, 835-842. [CrossRef] [PubMed] 
15. Yamaguchi, M.; Yoshida, H.; Hirose, F.; Inoue, Y.H.; Hayashi, Y.; Yamagishi, M.; Nishi, Y.; Tamai, K.; Sakaguchi, K.; Matsukage, A. Ectopic expression of BEAF32A in the Drosophila eye imaginal disc inhibits differentiation of photoreceptor cells and induces apoptosis. Chromosoma 2001, 110, 313-321. [CrossRef] [PubMed]

16. Ali, H.S.; Ramadan, M.T.; Ragab, G.H.; Kamil, M.M.; Eissa, H.A. Optimizing browning capacity of eggplant rings during storage before frying. J. Am. Sci. 2011, 7, 579-592.

17. Koh, E.; Surh, J. Food types and frying frequency affect the lipid oxidation of deep frying oil for the preparation of school meals in Korea. Food Chem. 2015, 174, 467-472. [CrossRef]

18. Volden, J.; Borge, G.I.A.; Hansen, M.; Wicklund, T.; Bengtsson, G.B. Processing (blanching, boiling, steaming) effects on the content of glucosinolates and antioxidant-related parameters in cauliflower (Brassica oleracea L. ssp. botrytis). LWT Food Sci. Technol. 2009, 42, 63-73. [CrossRef]

19. Zhang, M.; Tang, J.; Mujumdar, A.S.; Wang, S. Trends in microwave-related drying of fruits and vegetables. Trends Food Sci. Technol. 2006, 17, 524-534. [CrossRef]

20. Barba, A.A.; Calabretti, A.; D’Amore, M.; Piccinelli, A.L.; Rastrelli, L. Phenolic constituents levels in cv. Agria potato under microwave processing. LWT Food Sci. Technol. 2008, 41, 1919-1926. [CrossRef]

21. Buratti, S.; Cappa, C.; Benedetti, S.; Giovanelli, G. Influence of cooking conditions on nutritional properties and sensory characteristics interpreted by e-senses: Case-study on selected vegetables. Foods 2020, 9, 607. [CrossRef] [PubMed]

22. Natella, F.; Belelli, F.; Ramberti, A.; Scaccini, C. Microwave and traditional cooking methods: Effect of cooking on antioxidant capacity and phenolic compounds content of seven vegetables. J. Food Biochem. 2010, 34, 796-810. [CrossRef]

23. Faller, A.L.K.; Fialho, E. The antioxidant capacity and polyphenol content of organic and conventional retail vegetables after domestic cooking. Food Res. Int. 2009, 42, 210-215. [CrossRef]

24. AL-Janabi, A.A.H.S.; AL-Rubeey, S.A.H. Detection of antimicrobial activity of solanum melogena L. (Egg plant) against pathogenic microorganisms. Pharmacogn. J. 2010, 2, 35-39. [CrossRef]

25. Arkoub-Djermoune, L.; Boulekbache-Makhlouf, L.; Zeghichi-Hamri, S.; Bellili, S.; Boukhalfa, F.; Madani, K. Influence of the thermal processing on the physico-chemical properties and the antioxidant activity of a solanaceae vegetable: Eggplant. J. Food Qual. 2016, 39, 181-191. [CrossRef]

26. Kim, R. A study of physiological activities of the thermal treated eggplant on the skin. KSBB J. 2016, 31, 151-157. [CrossRef]

27. Hayat, K. Impact of drying methods on the functional properties of peppermint (Mentha piperita L.) leaves. Sci. Lett. 2020, 8 , 36-42.

28. Noreen, H.; Semmar, N.; Farman, M.; McCullagh, J.S.O. Measurement of total phenolic content and antioxidant activity of aerial parts of medicinal plant Coronopus didymus. Asian Pac. J. Trop. Med. 2017, 10, 792-801. [CrossRef]

29. Hayat, K.; Zhang, X.; Chen, H.; Xia, S.; Jia, C.; Zhong, F. Liberation and separation of phenolic compounds from citrus mandarin peels by microwave heating and its effect on antioxidant activity. Sep. Purif. Technol. 2010, 73, 371-376. [CrossRef]

30. Alajmi, M.F.; Alam, P.; Rehman, M.T.; Husain, F.M.; Khan, A.A.; Siddiqui, N.A.; Hussain, A.; Kalam, M.A.; Parvez, M.K. Interspecies anticancer and antimicrobial activities of genus solanum and estimation of rutin by validated UPLC-PDA Method. Evid.-Based Complement. Altern. Med. 2018, 2018. [CrossRef]

31. He, J.; Yin, T.; Chen, Y.; Cai, L.; Tai, Z.; Li, Z.; Liu, C.; Wang, Y.; Ding, Z. Phenolic compounds and antioxidant activities of edible flowers of Pyrus pashia. J. Funct. Foods 2015, 17, 371-379. [CrossRef]

32. Sukprasansap, M.; Sridonpai, P.; Phiboonchaiyanan, P.P. Eggplant fruits protect against DNA damage and mutations. Mutat. Res. Mol. Mech. Mutagen. 2019, 813, 39-45. [CrossRef] [PubMed]

33. Kaur, C.; Nagal, S.; Nishad, J.; Kumar, R.; Sarika. Evaluating eggplant (Solanum melongena L) genotypes for bioactive properties: A chemometric approach. Food Res. Int. 2014, 60, 205-211. [CrossRef]

34. Hayat, K.; Abbas, S.; Hussain, S.; Shahzad, S.A.; Tahir, M.U. Effect of microwave and conventional oven heating on phenolic constituents, fatty acids, minerals and antioxidant potential of fennel seed. Ind. Crops Prod. 2019, 140, 111610. [CrossRef]

35. AL Juhaimi, F.; Musa Özcan, M.; Ghafoor, K.; Babiker, E.E. The effect of microwave roasting on bioactive compounds, antioxidant activity and fatty acid composition of apricot kernel and oils. Food Chem. 2018, 243, 414-419. [CrossRef]

36. Douiri-Bedoui, I.; Abdellaoui, H.; Alexa, R.; Jacolot, P.; Druon, C.; Tessier, F.J.; Laguerre, J.-C. Optimization of microwave cooking of courgette in terms of nutrient preservation and energy consumption. Procedia Food Sci. 2011, 1, 805-813. [CrossRef]

37. Uchida, K.; Tomita, H.; Takemori, T.; Takamura, H. Effects of grilling on total polyphenol content and antioxidant capacity of eggplant (Solanum melongena L.). J. Food Sci. 2017, 82, 202-207. [CrossRef]

38. Xu, Y.; Chen, Y.; Cao, Y.; Xia, W.; Jiang, Q. Application of simultaneous combination of microwave and steam cooking to improve nutritional quality of cooked purple sweet potatoes and saving time. Innov. Food Sci. Emerg. Technol. 2016, 36, 303-310. [CrossRef]

39. Wongsa, P.; Khampa, N.; Horadee, S.; Chaiwarith, J.; Rattanapanone, N. Quality and bioactive compounds of blends of Arabica and Robusta spray-dried coffee. Food Chem. 2019, 283, 579-587. [CrossRef]

40. Perrone, D.; Farah, A.; Donangelo, C.M. Influence of coffee roasting on the incorporation of phenolic compounds into melanoidins and their relationship with antioxidant activity of the brew. J. Agric. Food Chem. 2012, 60, 4265-4275. [CrossRef]

41. Wei, F.; Tanokura, M. Coffee in Health and Disease Prevention; Elsevier: Amsterdam, The Netherlands, 2015; ISBN 978-0-12-409517-5.

42. Pastoriza, S.; Rufián-Henares, J.A. Contribution of melanoidins to the antioxidant capacity of the Spanish diet. Food Chem. 2014, 164, 438-445. [CrossRef] [PubMed] 
43. Ludwig, I.A.; Bravo, J.; De Peña, M.P.; Cid, C. Effect of sugar addition (torrefacto) during roasting process on antioxidant capacity and phenolics of coffee. LWT Food Sci. Technol. 2013, 51, 553-559. [CrossRef]

44. Das, S.; Raychaudhuri, U.; Falchi, M.; Bertelli, A.; Braga, P.C.; Das, D.K. Cardioprotective properties of raw and cooked eggplant (Solanum melongena L). Food Funct. 2011, 2, 395. [CrossRef] [PubMed]

45. Zaro, M.J.; Ortiz, L.C.; Keunchkarian, S.; Chaves, A.R.; Vicente, A.R.; Concellón, A. Chlorogenic acid retention in white and purple eggplant after processing and cooking. LWT Food Sci. Technol. 2015, 64, 802-808. [CrossRef]

46. Guo, Q.; Sun, D.-W.; Cheng, J.-H.; Han, Z. Microwave processing techniques and their recent applications in the food industry. Trends Food Sci. Technol. 2017, 67, 236-247. [CrossRef]

47. del Pilar Ramírez-Anaya, J.; Samaniego-Sánchez, C.; Castañeda-Saucedo, M.C.; Villalón-Mir, M.; de la Serrana, H.L.-G. Phenols and the antioxidant capacity of Mediterranean vegetables prepared with extra virgin olive oil using different domestic cooking techniques. Food Chem. 2015, 188, 430-438. [CrossRef]

48. Chumyam, A.; Whangchai, K.; Jungklang, J.; Faiyue, B.; Saengnil, K. Effects of heat treatments on antioxidant capacity and total phenolic content of four cultivars of purple skin eggplants. Sci. Asia 2013, 39, 246. [CrossRef]

49. Hanson, P.M.; Yang, R.-Y.; Tsou, S.C.S.; Ledesma, D.; Engle, L.; Lee, T.-C. Diversity in eggplant (Solanum melongena) for superoxide scavenging activity, total phenolics, and ascorbic acid. J. Food Compos. Anal. 2006, 19, 594-600. [CrossRef]

50. Mennella, G.; Lo Scalzo, R.; Fibiani, M.; D'Alessandro, A.; Francese, G.; Toppino, L.; Acciarri, N.; de Almeida, A.E.; Rotino, G.L. Chemical and bioactive quality traits during fruit ripening in eggplant (S. melongena L.) and allied species. J. Agric. Food Chem. 2012, 60, 11821-11831. [CrossRef]

51. Prohens, J.; Whitaker, B.D.; Plazas, M.; Vilanova, S.; Hurtado, M.; Blasco, M.; Gramazio, P.; Stommel, J.R. Genetic diversity in morphological characters and phenolic acids content resulting from an interspecific cross between eggplant, Solanum melongena, and its wild ancestor (S. incanum). Ann. Appl. Biol. 2013, 162, 242-257. [CrossRef]

52. Stommel, J.R.; Whitaker, B.D. Phenolic acid content and composition of eggplant fruit in a germplasm core subset. J. Am. Soc. Hortic. Sci. 2003, 128, 704-710. [CrossRef]

53. Plazas, M.; Prohens, J.; Cuñat, A.; Vilanova, S.; Gramazio, P.; Herraiz, F.; Andújar, I. Reducing capacity, chlorogenic acid content and biological activity in a collection of scarlet (Solanum aethiopicum) and gboma (S. macrocarpon) eggplants. Int. J. Mol. Sci. 2014, 15, 17221-17241. [CrossRef] [PubMed] 